Article

\title{
Analysis of Preparation and Properties on Shape Memory Hydrogenated Epoxy Resin Used for Asphalt Mixtures
}

\author{
Biao Ma ${ }^{1}$, Xueyan Zhou ${ }^{1, *}$, Kun Wei ${ }^{1}$, Yanzhen Bo ${ }^{1}$ and Zhanping You ${ }^{1,2}$ \\ 1 Key Laboratory for Special Area Highway Engineering of Ministry of Education, Chang'an University, \\ Xi'an 710064,China; mabiaochd@163.com (B.M.); Weikun@chd.edu.cn (K.W.); chd_byz@163.com (Y.B.); \\ zyou@mtu.edu (Z.Y.) \\ 2 Department of Civil and Engineering Environment, Michigan Technological University, \\ Houghton, MI 49931, USA \\ * Correspondence: 2015021014@chd.edu.cn; Tel.: +86-181-4941-5972
}

Academic Editor: Richard Yong Qing Fu

Received: 18 April 2017; Accepted: 15 May 2017; Published: 23 May 2017

\begin{abstract}
The objective of this investigation is to prepare the shape memory hydrogenated epoxy resin used for asphalt mixtures (SM-HEP-AM) and study its properties. The shape memory hydrogenated epoxy resin (SM-HEP) is prepared using hydrogenated bisphenol A epoxy resin (AL-3040), polypropylene glycol diglycidylether diacrylate (JH-230), and isophorone diamine (IPDA). The formulations of the SM-HEP-AM are obtained by the linearly fitted method. The thermo-mechanical property, molecular structure, and shape-memory performance of the SM-HEP-AM are studied. The glass-transition temperature $\left(T_{\mathrm{g}}\right)$ is determined using the differential scanning calorimeter (DSC). The results proved that the $T_{\mathrm{g}}$ level increased when the JH-230 content decreased. The thermo-mechanical property of the SM-HEP-AM is measured by dynamical mechanical analysis (DMA). The storage modulus of the SM-HEP-AM decreased with the increase in the JH-230 content. The above phenomena are attributed to the change in the JH-230 content. The shape memory performance results of the SM-HEP-AM indicate that specimen deformation can completely recover after only several minutes at $T_{\mathrm{g}}+10^{\circ} \mathrm{C}$ and $T_{\mathrm{g}}+20^{\circ} \mathrm{C}$. The shape recovery time of the SM-HEP-AM increases with increased JH-230 content, and the change between the shape recovery time and $\mathrm{JH}-230$ content gradually decreased as the temperature increased. The deformation recovery performance of asphalt mixture with and without the SM-HEP-AM $\left(T_{\mathrm{g}}=40^{\circ} \mathrm{C}\right)$ was tested by the deformation recovery test. This was used to prove that the SM-HEP-AM helps to improve the deformation recovery performance of the asphalt mixture.
\end{abstract}

Keywords: road engineering; asphalt mixture; shape-memory hydrogenated epoxy resin; glass-transition temperature; shape-memory performance

\section{Introduction}

Rutting caused by heavy loads at a high temperature is one of the typical distresses in asphalt pavements. Rutting has an important influence on the performance of asphalt pavements during their life period [1]. When the vehicle load is applied to the asphalt pavement surface at high temperatures, deformation of the asphalt mixture will occur. Because the asphalt mixture is one kind of self-healing material, the deformation can partially recover once the load is removed. Since the primary self-healing principle of asphalt mixture is the capillary flow of the bitumen through the cracks at high temperatures, the self-healing process of asphalt mixture is a very slow process and the cracks may need a long time to completely self-heal [2]. Furthermore, in practice, the asphalt pavements undergo continual vehicle loads, and the cracks of asphalt mixture are impossible to completely self-heal [3]. Meanwhile, there 
are still variable amounts of irreversible deformation that remain in the asphalt mixture, which will result in a very small permanent residual strain. The accumulation of millions of permanent residual strains occurs due to repeat vehicle loadings and results in the rutting of asphalt pavements [4-7].

Several researchers have studied effective measurements for reducing the influence of rutting on the asphalt pavement performance. Kumar et al. [8] studied the rutting behavior of a base layer reinforced with geocell and found that geocell reinforcement is effective in reducing the rutting and improving the performance of the unsurfaced rural pavements. Sun [9] studied the effective prediction method of rutting on the asphalt pavement. Shafabakhsh et al. [10] found that the rutting resistance of a Nano $\mathrm{TiO}_{2} / \mathrm{SiO}_{2}$ modified asphalt mixture had been improved. Ziari et al. [11] studied the influence of the nanotechnology, zycosoil, on rutting resistance and found that the asphalt modified with nanotechnology zyco-soil displayed a remarkably good performance. Though these measurements have improved the rutting resistance of asphalt pavements, the process is almost passive. The main objective of this research is to find an approach that can actively adjust the asphalt pavement recoverability. Therefore, the rutting resistance of asphalt pavements may be improved.

Shape-memory polymers (SMPs) are smart polymers that can assume a temporary shape and then recover to their original shape upon the action of an external stimulus, such as temperature (set by direct or indirect ways), an electric field, or moisture [12,13]. The SMPs have the advantages of an excellent process-ability, low recovery temperature, and high elastic deformation compared with the other shape-memory materials. Therefore, SMPs have been widely applied to the fields of textiles, biomedicines, and aerospace deployable structures [14]. Some researchers have used SMPs to make the actuator of the space deployable structure, including an expandable hinge [15], deployable antennas [16], solar arrays, switchable information carriers [17], encoded information [18], etc. The biodegradable SMP was used by Strandman et al. [19] to prepare surgical sutures. This is due to their good shape memory performance, excellent stiffness, and environmental durability.

The preferred thermoset SMPs stimulated by temperature are based on epoxy resins. The segments between the cross-links adapt to the external load via conformational rearrangements during the process of setting the temporary shape. The strain energy, stored in the above way, is released when the material is unloaded and heated above its $T_{\mathrm{g}}$ when the permanent shape is restored [20]. Fritzsche et al. [21] stated that phase-segregated poly (ester urethane) with crystallizable switching segments of poly(1,4-butylene adipate) excels as a high-performance temperature-memory polymer. Bothe et al. [22] studied how to teach a thermoplastic polyurethane elastomer a completely stress-free, bidirectional motion. The epoxy resins are selected for their favorable properties, such as their high stiffness in both glassy and rubbery stages, and high shape memory performance. Even more important, the formulations of the shape-memory epoxy resin can be easily changed to meet the different requirements of given applications [23-26].

Previous studies on the application of the thermoset SMPs have mainly focused on the biomedical, aerospace, and textile fields. There are still no observations on applying the thermoset SMPs to the asphalt mixture. Therefore, with the aim of improving the rutting resistance of asphalt pavements, a novel shape-memory hydrogenated epoxy resin (SM-HEP) was prepared using the hydrobisphenol A epoxy resin, polypropylene glycol diglycidyl ether (JH-230), and isophorone diamine. Furthermore, asphalt mixture mixed with the SM-HEP would have a much longer life-cycle compared to the matrix asphalt mixture, thus reducing the estimated cost of the asphalt mixed with the SM-HEP. The $T_{\mathrm{g}}$ can be actively changed by adjusting the epoxy resin/flexibilizer stoichiometric ratio [20]. The cross-link density, chain flexibility, and aggregation state of the SM-HEP-AM network can be controlled by adjusting the JH-230 content. The preparation and characterization of the SM-HEP-AM were studied in this paper. The corresponding preparation process, thermal property, glass-transition temperature $\left(T_{\mathrm{g}}\right)$, molecular structure, dynamic mechanical property, and shape-memory performance were investigated in detail. More specially, the influences of the epoxy resin/flexibilizer stoichiometric ratio on the properties of SM-HEP were studied. 


\section{Materials and Methods}

\subsection{Materials}

The epoxy resin in this study is hydrogenated bisphenol A epoxy resin (AL-3040) with an epoxy value of $0.43 \mathrm{eq} / 100 \mathrm{~g}$. The flexibilizer is polypropylene glycol diglycidyl ether (JH-230) with an average molecular weight of $2500 \mathrm{~g} / \mathrm{mol}$, viscosity at $25{ }^{\circ} \mathrm{C}$ of $425 \mathrm{mPas}$, and density of $0.925 \mathrm{~g} / \mathrm{cm}^{3}$. The epoxy resin and flexibilizer in this study were both manufactured by Yantai Aolifu Chemical Industry Co., Ltd. (Yantai, China). The isophorone diamine (IPDA) with a $170.3 \mathrm{~g} / \mathrm{mol}$ average molecular weight was used as a curing agent, which was purchased from Hubei Giant Technology Co., Ltd. (Hubei, China). The chemical structures of these materials are shown in Figure 1.

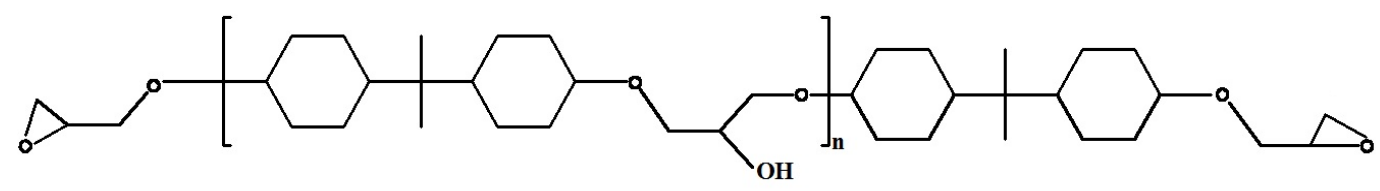

(a)

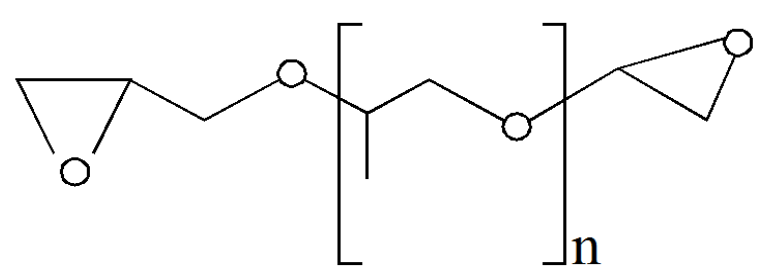

(b)

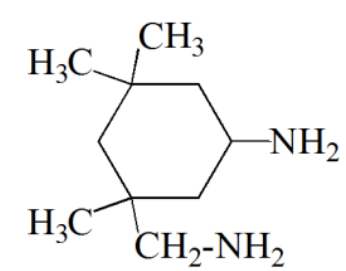

(c)

Figure 1. The chemical structures of the AL-3040, JH-230, and IPDA: (a) hydrobisphenol A epoxy resin (AL-3040); (b) polypropylene glycol diglycidyl ether (JH-230); and (c) isophorone diamine (IPDA).

\subsection{Preparation of the Shape Memory Hydrogenated Epoxy Resin (SM-HEP)}

The SM-HEP consists of the hydrobisphenol A epoxy resin (AL-3040), polypropylene glycol diglycidyl ether (JH-230), and curing agent, i.e., the isophorone diamine (IPDA) in certain proportions, which were mixed at $60{ }^{\circ} \mathrm{C}$ and placed into a beaker to blend. Then, the prepolymer solution was degassed at $60{ }^{\circ} \mathrm{C}$ in a vacuum oven to obtain a bubble-free prepolymer. After degassing, the prepolymer solution was then placed into the polytetrafluoroethylene mold. A thermal curing program was performed at $120^{\circ} \mathrm{C}$ for four hours. During the thermal curing program, the flexible groups in the JH-230 were introduced into the network structure of the AL-3040, and the active hydrogen of IPDA completely reacted with the epoxy group in the AL-3040. After the curing process, the SM-HEP specimens were demolded for the tensile-recovery shape memory test and cut into rectangular shapes for dynamic mechanical analysis (DMA). The glass-transition temperature $\left(T_{\mathrm{g}}\right)$ of the SM-HEP can be actively controlled by adjusting the epoxy resin/flexibilizer stoichiometric ratio [20].

To prepare the SM-HEP with an appropriate level of $T_{\mathrm{g}}$ for the asphalt mixture (SM-HEP-AM), the SM-HEP with an epoxy resin/flexibilizer stoichiometric ratio between 0.90:0.10-0.98:0.02 was firstly synthesized. Then, the differential scanning calorimeter (DSC) (NETZSCH Instruments, Bremen, Germany) was used to measure the SM-HEP $T_{\mathrm{g}}$, and the relationship between the $T_{\mathrm{g}}$ and JH-230 content was fitted by the linear fitting method. According to the fitted equation, an appropriate JH-230 content with the required $T_{\mathrm{g}}$ could be back-calculated. Finally, the formulations of SM-HEP-AM were obtained by the repeated fitting-back-calculation process.

\subsection{Preparation of the Asphalt Mixture Mixed with the Shape Memory Hydrogenated Epoxy Resin (SM-HEP)}

Firstly, the aggregate and mineral powders were heated in an oven at $170{ }^{\circ} \mathrm{C}$ for four hours. Secondly, the asphalt was heated until it completely melted, the asphalt with a mass ratio of $6 \%$ was 
then added to the heated aggregate, and the mixture was stirred at $180{ }^{\circ} \mathrm{C}$ for $90 \mathrm{~s}$ in an asphaltmischer. Thirdly, the mineral powder with a mass ratio of $6 \%$ was added to the asphalt mixture and the mixture was stirred at $180^{\circ} \mathrm{C}$ for $90 \mathrm{~s}$ in an asphaltmischer. Then, the SM-HEP (specimen JH-230-0.0796) with a mass ratio of $1 \%$ was added to the asphalt mixture following the same method. Finally, the asphalt mixture rutting test (T0719-2011) [27] was used to prepare samples for the deformation recovery performance.

\subsection{Test Methods}

\subsubsection{Differential Scanning Calorimeter (DSC)}

The glass-transition temperature $\left(T_{\mathrm{g}}\right)$ of the shape memory hydrogenated epoxy resin used for the asphalt mixtures was measured on a 200F3 NETZSCH Instrument. The specimens were heated from -40 to $140{ }^{\circ} \mathrm{C}$ in the protective atmosphere of $\mathrm{N}_{2}$ with a heating rate of $10{ }^{\circ} \mathrm{C} / \mathrm{min}$. The specimens were milled as powder and their weights ranged from 9 to $12 \mathrm{mg}$. The temperature holding time was $3 \mathrm{~min}$.

\subsubsection{Fourier Transform Infrared Spectroscopy (FT-IR)}

The molecular structures of the shape memory hydrogenated epoxy resin used for the asphalt mixtures were investigated by an Fourier transform infrared (FT-IR) spectrometer (TENSOR 37) developed by the BRUKER Instruments (Karlsruhe, Germany). The FT-IR spectra ranged from 3000 to $300 \mathrm{~cm}^{-1}$. The test method was the $\mathrm{KBr}$ compression method and the spectrums were then obtained after 16 scans. The device was driven by "OPUS" software (7.5.18, BRUKER Instruments, Karlsruhe, Germany, 2014) for the acquisition and data processing.

\subsubsection{Dynamic Mechanical Analysis (DMA)}

The thermo-mechanical properties of the shape memory hydrogenated epoxy resin used for the asphalt mixtures were investigated using a DMA Q800 system (TA Instruments, New Castlee, DE, USA) in a multi-frequency-strain mode from 30 to $120^{\circ} \mathrm{C}$. The specimen dimensions were $35 \times 10 \times 4 \mathrm{~mm}^{3}$. The specimens were heated at a rate of $3{ }^{\circ} \mathrm{C} / \mathrm{min}$, and an applied strain of $0.1 \%$ was oscillated at a constant frequency of $1 \mathrm{~Hz}$. The amplitude was $20 \mu \mathrm{m}$.

\subsubsection{Tensile-Recovery Shape Memory Test}

The dumbbell-shaped specimens were used to evaluate the shape-memory performance of the shape memory hydrogenated epoxy resin used for the asphalt mixtures. The specimens with five different formulations were measured under each condition. The tensile-recovery shape memory test was performed according to the following steps: (i) The original length of the specimen was recorded as $L_{0}$. The dumbbell-shaped specimen was setup in the clamp of the tensile instrument we prepared. Then, a constant temperature system was heated up to a certain temperature by circulating hot water; the hot water was then put into the tensile instrument equipped with the specimen. The specimen was held for $5 \mathrm{~min}$ for full heating. The temperatures used were set to $T_{\mathrm{g}}-10, T_{\mathrm{g}}, T_{\mathrm{g}}+10$, and $T_{\mathrm{g}}+20^{\circ} \mathrm{C}$; (ii) The specimen was stretched to a certain length. The stretch rate was $5 \mathrm{~cm} / \mathrm{min}$ and the length was recorded as $L_{1}$. The stretched specimen was then quickly cooled with a constant external force and the tensile deformation was frozen. Afterwards, the stretched specimen was dipped into a cold water bottle $\left(-10^{\circ} \mathrm{C}\right)$ in the refrigerator for $10 \mathrm{~min}$. The length was recorded as $L_{2}$ at this moment; (iii) To quantify the shape-memory performance, the stretched specimen was placed into an electric-heated thermostatic water bath set to the temperature at which the specimen was deformed, and the shape recovery process was observed. The recovery time was recorded as the point at which the specimen did not change. Five parallel specimens for each of the SM-HEP-AM were measured at the designated temperature to obtain the average recovery time. This recovery time was designated as the shape 
recovery time for that temperature. The length was then recorded as $L_{3}$. The shape fixity ratio $\left(R_{\mathrm{f}}\right)$ and shape recovery ratio $\left(R_{\mathrm{r}}\right)$ were calculated using Equations (1) and (2).

$$
\begin{aligned}
& R_{\mathrm{f}}=\frac{\left(L_{2}-L_{0}\right)}{\left(L_{1}-L_{0}\right)} \times 100 \% \\
& R_{\mathrm{r}}=\frac{\left(L_{2}-L_{3}\right)}{\left(L_{2}-L_{0}\right)} \times 100 \%
\end{aligned}
$$

\subsubsection{Deformation Recovery Test}

Rectangular samples were used to evaluate the deformation recovery performance of the asphalt mixture and the asphalt mixture mixed with the SM-HEP (specimen JH-230-0.0796). A deformation recovery test was performed according to the following steps: (i) The intermediate loading position of the rectangular samples was marked, a constant temperature system was maintained at $10^{\circ} \mathrm{C}$ by an environmental cabinet, and the sample was held for $30 \mathrm{~min}$ in the environmental cabinet; (ii) The failure load of the sample was obtained with a compression rate of $5 \mathrm{~cm} / \mathrm{min}$ used by the three point bending test of the universal testing machine; (iii) The bending creep test of the universal testing machine was used to load the sample, a failure load of $20 \%$ was oscillated at $10{ }^{\circ} \mathrm{C}$, and the holding time was $6 \mathrm{~min}$. The testing equipment is shown in Figure 2; (iv) The sample was immediately removed after loading, the sample was kept at room temperature for $3 \mathrm{~min}$, and the deformation of the loading position was recorded as $D_{1}$. (v) The sample was put into a water bath set at $60{ }^{\circ} \mathrm{C}$ for $60 \mathrm{~s}$ and $120 \mathrm{~s}$ before being removed, and the deformation of the loading position was recorded as $\mathrm{D}_{2}$. (vi) To quantify the deformation recovery, the deformation recovery ratio (R) was calculated using Equation (3).

$$
\mathrm{R}=\left(\frac{\mathrm{D}_{1}-\mathrm{D}_{2}}{\mathrm{D}_{1}}\right) \times 100 \%
$$

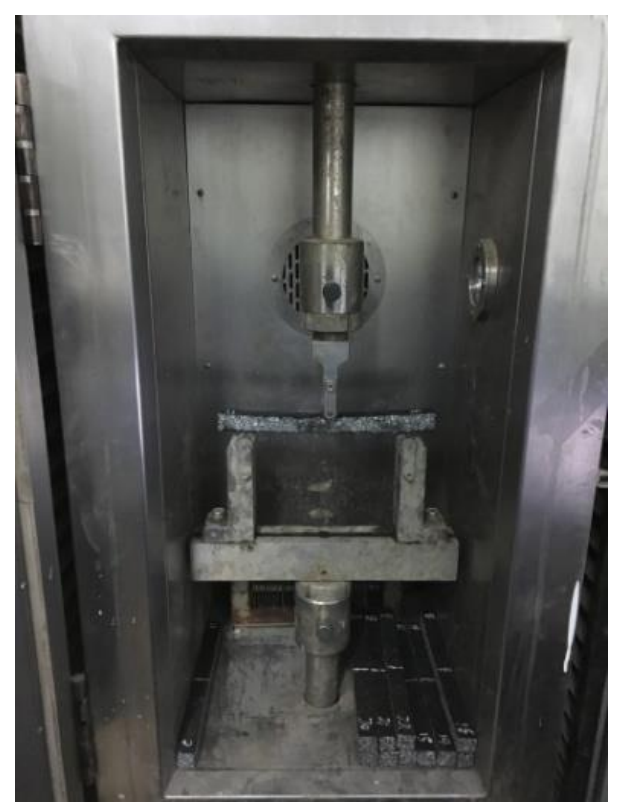

Figure 2. The testing equipment of the deformation recovery test.

\section{Results and Analysis}

\subsection{Controllable Preparation Result of the Shape Memory Hydrogenated Epoxy Resin (SM-HEP)}

The SM-HEP specimens were named JH-230 N; the " $\mathrm{N}$ " is the JH-230 molar mass of the specimens. The formulations of specimens JH-230 0.02-JH-230 0.10 are shown in Table 1. 
Table 1. Specimens and their specifications.

\begin{tabular}{cccc}
\hline Specimen & AL-3040 (mol) & JH-230 (mol) & IPDA (mol) \\
\hline JH-230 0.02 & 0.98 & 0.02 & 0.5 \\
JH-230 0.04 & 0.96 & 0.04 & 0.5 \\
JH-230 0.05 & 0.95 & 0.05 & 0.5 \\
JH-230 0.06 & 0.94 & 0.06 & 0.5 \\
JH-230 0.08 & 0.92 & 0.08 & 0.5 \\
JH-230 0.10 & 0.90 & 0.10 & 0.5 \\
\hline
\end{tabular}

To study the relationship between the JH-230 content and $T_{\mathrm{g}}$, the $T_{\mathrm{g}}$ of the specimens with the specifications in Table 1 were tested by the differential scanning calorimeter (DSC). As can be seen in Figure 3, the SM-HEP $T_{\mathrm{g}}$ linearly decreased as the JH-230 content increased, which means that $T_{\mathrm{g}}$ could be changed by adjusting the JH-230 content. The $T_{\mathrm{g}}$ is a key characteristic parameter of the thermo-mechanical behaviour and shape recovery performance of SMPs. The flexible change in the $T_{\mathrm{g}}$ of the SM-HEP is a very useful feature that can expand the applications of the material to meet different demands.

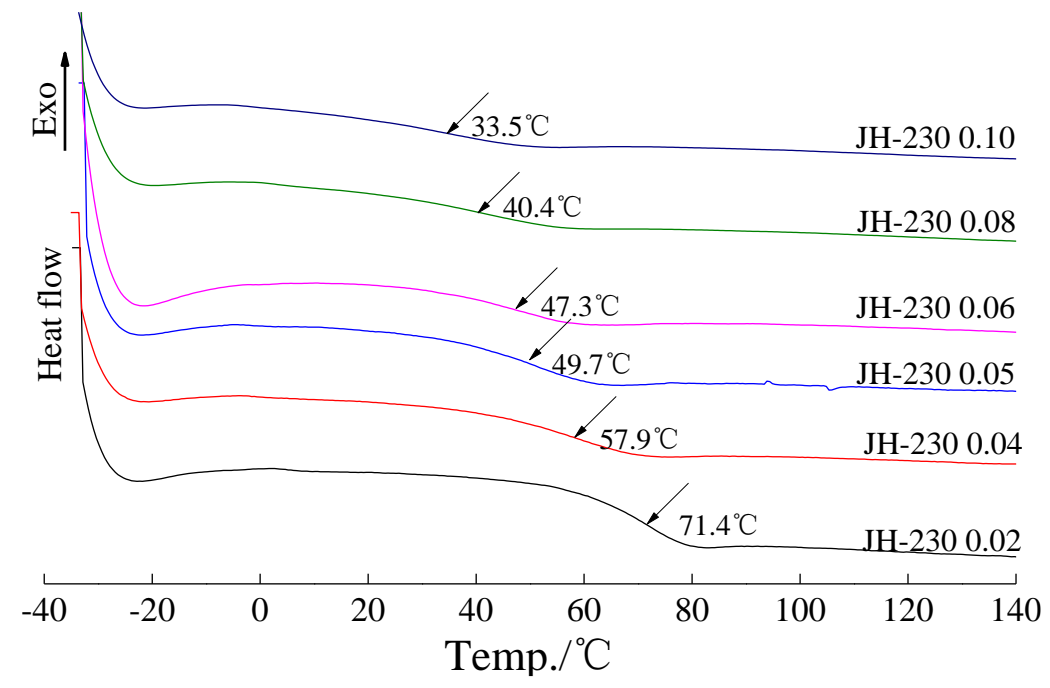

Figure 3. The second heating DSC curves of the shape-memory hydrogenated epoxy resin (heating flow $\left.=10^{\circ} \mathrm{C} / \mathrm{min}\right)$.

The $T_{\mathrm{g}}$ values obtained from the DSC curves are also marked in Figure 3. As shown in Figure 3, all SM-HEP specimens show $T_{\mathrm{g}}$ values ranging from 33.5 to $71.4^{\circ} \mathrm{C}$. The $T_{\mathrm{g}}$ values gradually decreased with an increased JH-230 content. To further study the relationship of the JH-230 content and $T_{\mathrm{g}}$, the relationship was fitted linearly.

Figure 4 shows the linear fit results. The preliminary linear fit equation is presented in Equation (4).

$$
Y=-4.56163 \times X+76.64286
$$

In Equation (4), $Y$ is the $T_{\mathrm{g}}$ of SM-HEP and $X$ is the JH-230 content. As can be seen in Figure 4 , the $T_{\mathrm{g}}$ of SM-HEP linearly decreased with the increase in the JH-230 content. The correlation coefficient $R^{2}$ is 0.9405 , which proves that the linear fit degree is high. The formulations of the SM-HEP with different $T_{\mathrm{g}}$ values can be back-calculated using Equation (4). 


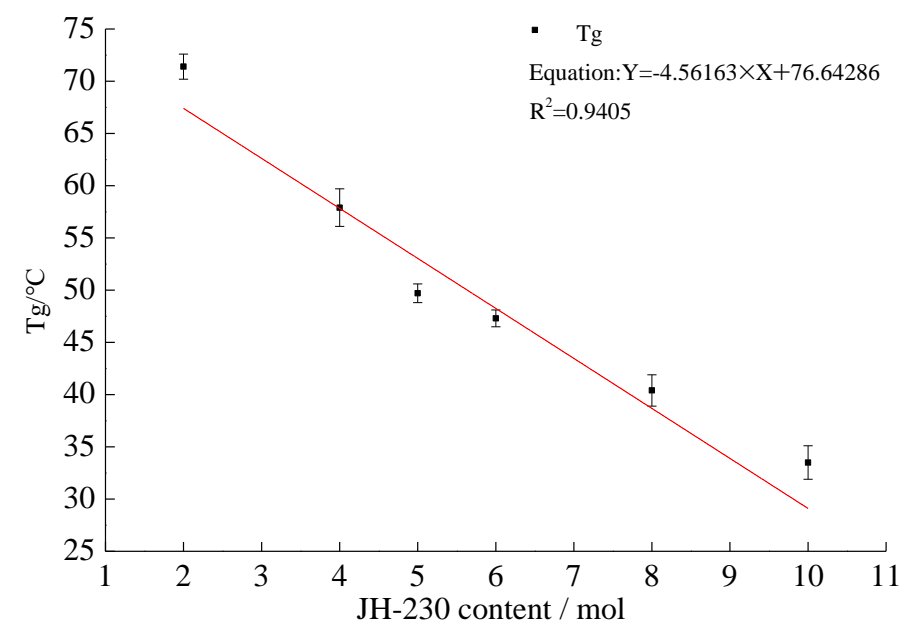

Figure 4. The linear fit of the JH-230 content and $T_{\mathrm{g}}$.

The SM-HEP studied in this paper was mainly used to reduce the accumulation of permanent deformation on an asphalt pavement at high temperatures and then improve the rutting resistance of the asphalt pavement. Due to the fact that SM-HEP can correct its temporary deformed shape and restore its original shape upon an external stimulus, the deformation temperature may be below the $T_{\mathrm{g}}$ of the SM-HEP [14]. When the temperature of the asphalt mixture ranges from 30 to $70{ }^{\circ} \mathrm{C}$, the cracks will start to self-heal [28]. The SM-HEP $T_{\mathrm{g}}$ used for the asphalt mixture was set as 40, 45, 50, 55, and $60{ }^{\circ} \mathrm{C}$ to investigate the improvement effect of the SM-HEP on the rutting resistance of the asphalt pavement. The back-calculated formulations of the SMP-HEP with $T_{\mathrm{g}}$ values of $40,45,50,55,60^{\circ} \mathrm{C}$ are shown in Table 2. The corresponding measured $T_{\mathrm{g}}$ values tested by DSC are displayed in Figure 5.

Table 2. Specimens with back-calculated formulations and their $T_{\mathrm{g}}$ values.

\begin{tabular}{ccccc}
\hline Specimen & AL-3040 (mol) & JH-230 (mol) & IPDA (mol) & Tg-Fitted $\left({ }^{\circ} \mathbf{C}\right)$ \\
\hline JH-230-0.0274 & 0.9726 & 0.0274 & 0.5 & 60 \\
JH-230-0.0407 & 0.9593 & 0.0407 & 0.5 & 55 \\
JH-230-0.0540 & 0.9460 & 0.0540 & 0.5 & 50 \\
JH-230-0.0678 & 0.9322 & 0.0678 & 0.5 & 45 \\
JH-230-0.0805 & 0.9805 & 0.0805 & 0.5 & 40 \\
\hline
\end{tabular}

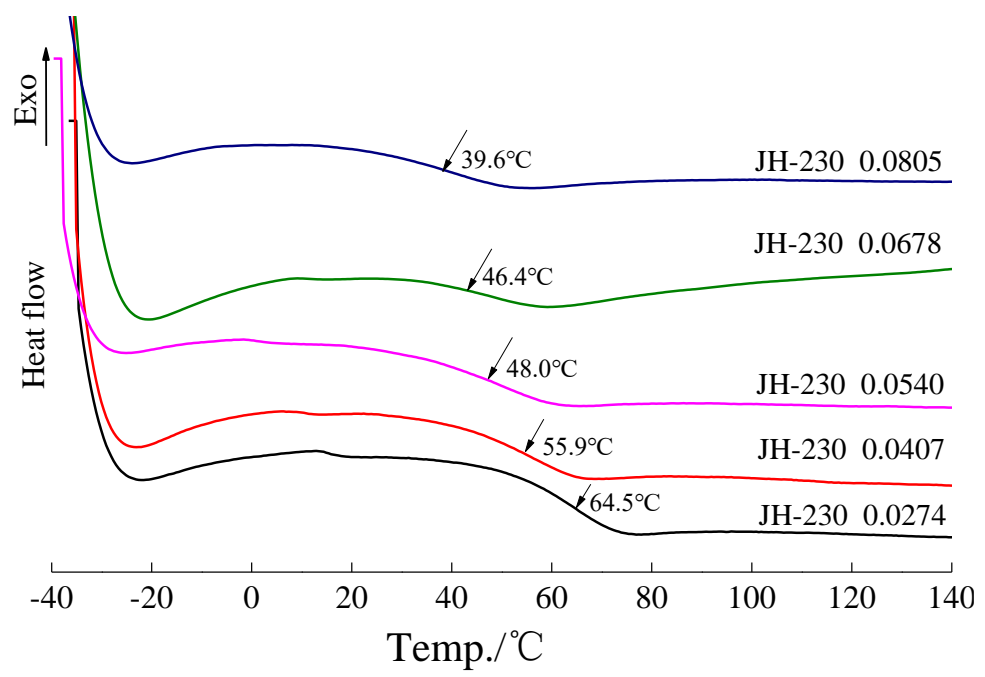

Figure 5. The second heating differential scanning calorimeter (DSC) curves of the shape-memory hydrogenated epoxy resin with inverse calculated formulations (heating flow $=10^{\circ} \mathrm{C} / \mathrm{min}$ ). 
According to Table 2 and Figure 5, the preliminary fitted $T_{\mathrm{g}}$ and measured $T_{\mathrm{g}}$ were inconsistent, especially for the specimen $\mathrm{JH}-2300.0274$, for which the difference was $4.5^{\circ} \mathrm{C}$. To ensure the accuracy of the controllable preparation result, the SM-HEP values in Tables 1 and 2 were both used to linearly fit the relationship of the JH-230 content and $T_{\mathrm{g}}$. The second linear fitting results are shown in Figure 6 .

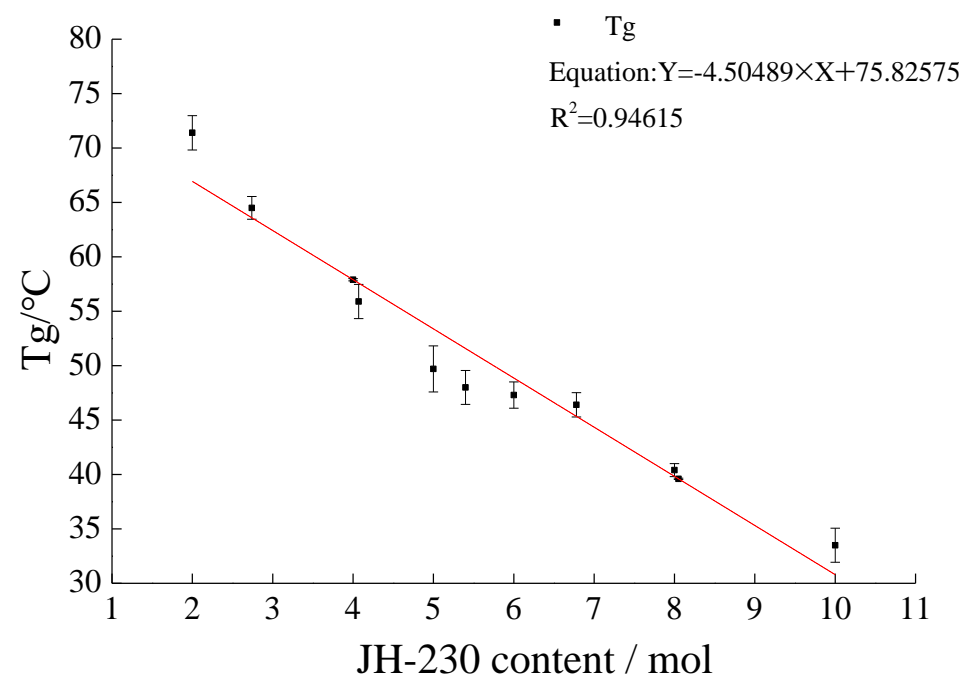

Figure 6. The second linear fitting relationship between the JH-230 content and the $T_{\mathrm{g}}$.

As shown in Figure 6, the $R^{2}$ of the second linear fitting results is 0.9462 , and the second linear fitting equation of $T_{\mathrm{g}}$ and the JH-230 content is shown in Equation (5).

$$
Y=-4.50489 \times X+75.82575
$$

With the same method, the corresponding back-calculated formulations of the $T_{\mathrm{g}}$ values of 40,45 , $50,55,60^{\circ} \mathrm{C}$ are shown in Table 3 . The measured $T_{\mathrm{g}}$ values tested by DSC are also displayed in Table 3 .

Table 3. Specimens with the second back-calculated formulations and their $T_{\mathrm{g}}$ values.

\begin{tabular}{ccccccc}
\hline Specimen & $\begin{array}{c}\text { AL-3040 } \\
(\mathbf{m o l})\end{array}$ & $\begin{array}{c}\text { JH-230 } \\
(\mathbf{m o l})\end{array}$ & $\begin{array}{c}\text { IPDA } \\
(\mathbf{m o l})\end{array}$ & $\begin{array}{c}\text { Tg-Fitted } \\
\left({ }^{\circ} \mathbf{C}\right)\end{array}$ & $\begin{array}{c}\text { Tg-Measured (Uppercase) } \\
\left({ }^{\circ} \mathbf{C}\right)\end{array}$ & $\begin{array}{c}\text { Error Bars } \\
\left({ }^{\circ} \mathbf{C}\right)\end{array}$ \\
\hline JH-230-0.0353 & 0.9647 & 0.0353 & 0.5 & 60 & 60.9 & 1.0 \\
JH-230-0.0463 & 0.9537 & 0.0463 & 0.5 & 55 & 55.5 & 0.7 \\
JH-230-0.0574 & 0.9426 & 0.0574 & 0.5 & 50 & 49.4 & 0.5 \\
JH-230-0.0685 & 0.9315 & 0.0685 & 0.5 & 45 & 44.8 & 0.4 \\
JH-230-0.0796 & 0.9204 & 0.0796 & 0.5 & 40 & 39.0 & 0.8 \\
\hline
\end{tabular}

In Table 3, the linear fitted $T_{\mathrm{g}}$ and measured $T_{\mathrm{g}}$ are almost the same. The 45 degrees contour map was used to prove that the controllable preparation result was accurate.

As can be seen in Figure 7, there is a high consistency between the fitted $T_{\mathrm{g}}$ of the specimen obtained by the second linear fitting equation and the measured $T_{\mathrm{g}}$ determined by the DSC. It was concluded that the second linear fit displays a good fitting precision and reproducibility. The $T_{\mathrm{g}}$ is not a fixed value, but is variable in a certain range. Therefore, the preparation results obtained by the linear fit method are reasonable. In conclusion, the formulations of the SM-HEP-AM are shown in Table 3. 


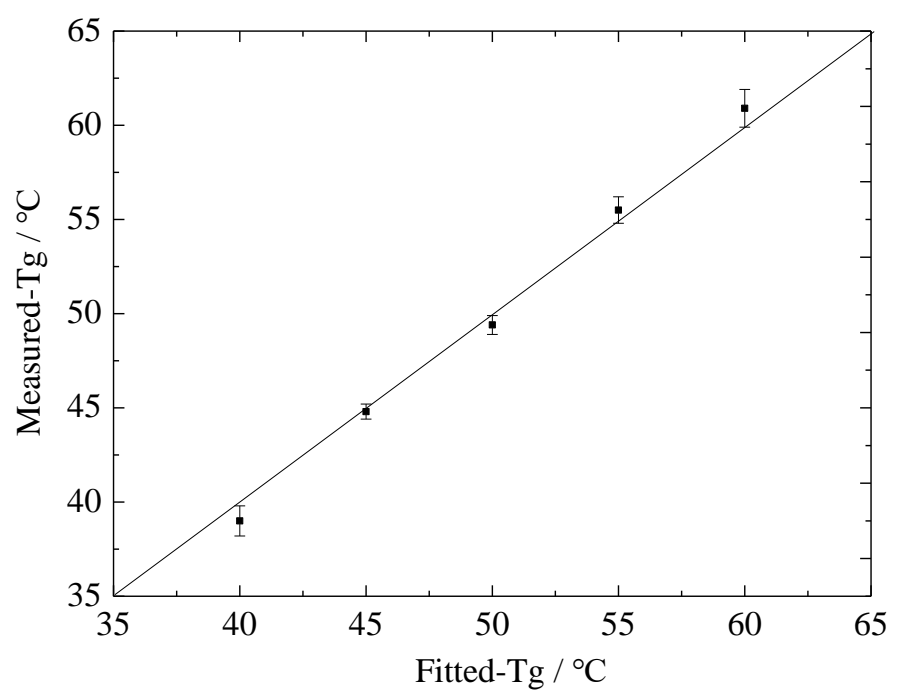

Figure 7. 45 degrees contour map of the SM-HEP $T_{\mathrm{g}}$.

3.2. The Thermal Property of the Shape Memory Hydrogenated Epoxy Resin Used for Asphalt Mixtures (SM-HEP-AM)

The DSC thermographs of the SM-HEP-AM are shown in Figure 8. The $T_{\mathrm{g}}$ values obtained from the DSCanalysis are also marked in Figure 8. The results demonstrated that the JH-230 content in the SM-HEP-AM had a significant effect on the $T_{\mathrm{g}}$. More specifically, the $T_{\mathrm{g}}$ decreased with an increased JH-230 content in the SM-HEP-AM. $T_{\mathrm{g}}$ is an essential transition temperature from the freezing to free-motion states of the segments in a polymer network. In the SM-HEP-AM network, the increased JH-230 content decreased the cross-link density and resulted in an increased mobility of the segments. Furthermore, the JH-230 molecular weight is $2500 \mathrm{~g} / \mathrm{mol}$ and its flexibility is high. Therefore, the chain flexibility of the SM-HEP-AM network improved as the JH-230 content increased, leading to a decrease in $T_{\mathrm{g}}[29]$.

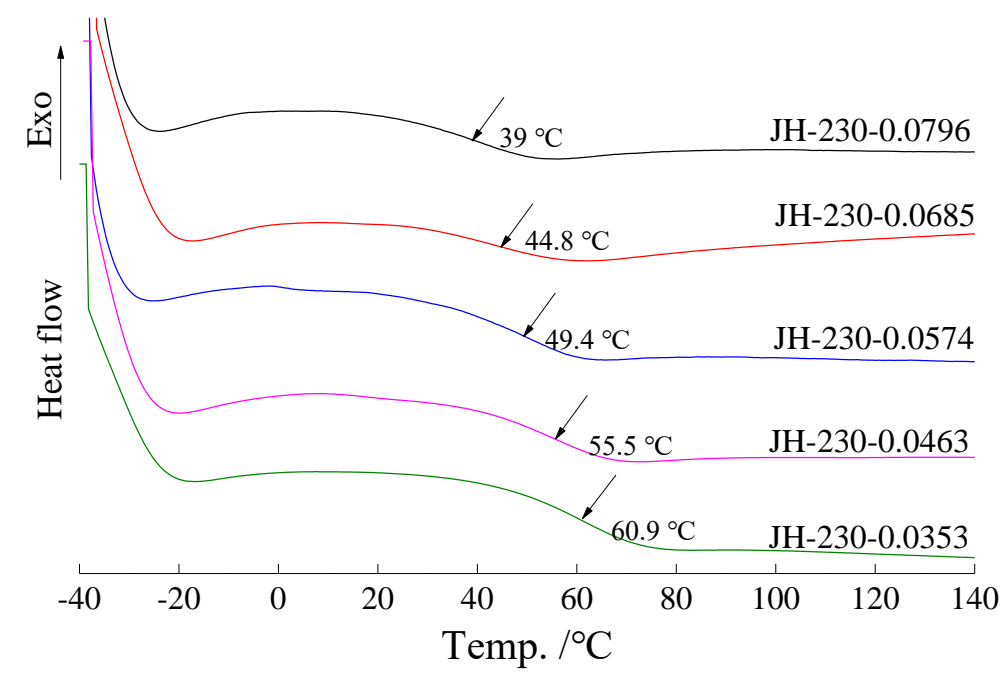

Figure 8. The second heating DSC curves of the SM-HEP-AM (heating flow $=10^{\circ} \mathrm{C} / \mathrm{min}$ ).

3.3. The Molecular Structure of the Shape Memory Hydrogenated Epoxy Resin Used for Asphalt Mixtures (SM-HEP-AM)

The chemical structures of the IPDA, JH-230, AL-3040, and SM-HEP-AM were confirmed through the FT-IR spectra in Figure 9. The absorption peak at $909 \mathrm{~cm}^{-1}$ on the infrared spectra of the AL-3040 
was attributed to the presence of epoxy groups. The disappearance of the absorption peak on the spectra of the SM-HEP-AM was due to the complete reaction of the epoxy groups in AL-3040 and the active hydrogen in IPDA. Meanwhile, it indicated that the SM-HEP-AM had been completely cured. The band at $1092 \mathrm{~cm}^{-1}$ on the spectra of the JH-230 and SM-HEP-AM corresponded to the C-O stretching vibration band in the raw materials $(\mathrm{JH}-230)$. The bands located around $1730 \mathrm{~cm}^{-1}$ in the $\mathrm{JH}-230$ and SM-HEP-AM were assigned to the $\mathrm{C}=\mathrm{O}$ stretching vibration band presented in the raw materials (JH-230). They also reflected the differences residing in the spectra, depending on the JH-230 content. These bands, with a very low intensity in specimen JH-230-0.0353, appear very visible on the spectra of specimen JH-230-0.0685 and specimen JH-230-0.0796. This indicated that the intensity of the bands at 1092 and $1730 \mathrm{~cm}^{-1}$ increased with an increased JH-230 content. It can be explained by the fact that there exists a large amount of $\mathrm{C}-\mathrm{O}$ and $\mathrm{C}=\mathrm{O}$ stretching vibration bands in JH-230, and with the increased JH-230 content, the $\mathrm{C}-\mathrm{O}$ and $\mathrm{C}=\mathrm{O}$ stretching vibration bands of SM-HEP-AM also increased. The peaks at 2859 and $2932 \mathrm{~cm}^{-1}$ were associated with the $-\mathrm{CH}_{3}$ symmetric stretching peak and saturation $\mathrm{C}-\mathrm{H}$ stretching vibration peak.

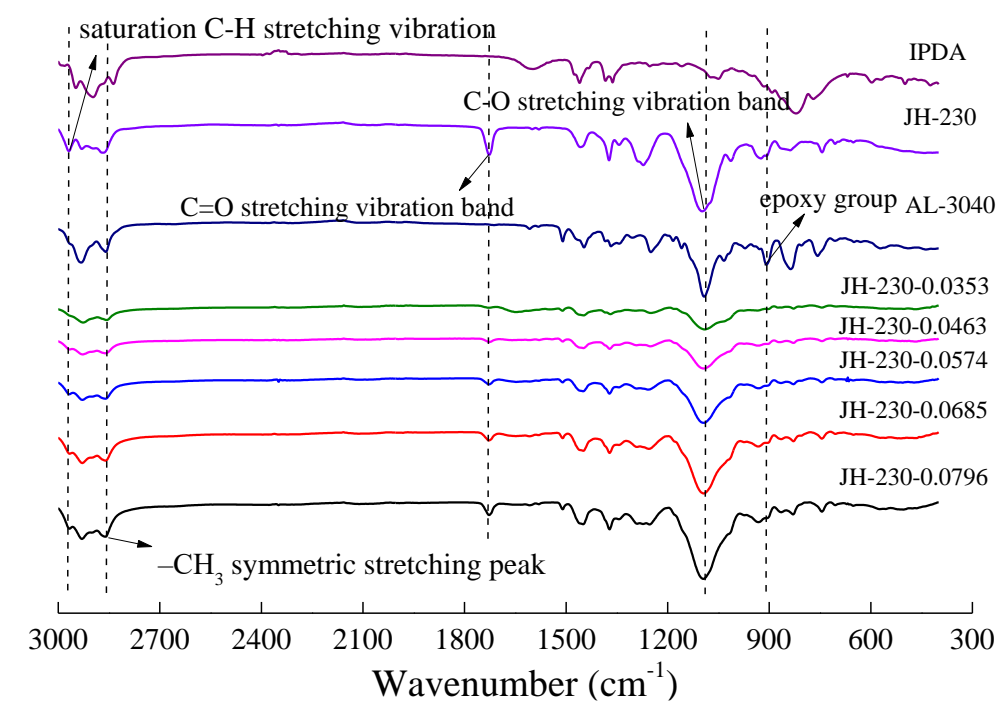

Figure 9. FT-IR Spectra of IPDA, JH-230, AL-3040, and the SM-HEP-AM.

\subsection{The Thermo-Mechanical Property of the Shape Memory Hydrogenated Epoxy Resin Used for Asphalt Mixtures (SM-HEP-AM)}

The storage modulus ( $\left.\mathrm{E}^{\prime}\right)$ values of the SM-HEP-AM are shown in Figure 10a. The changes in the $\mathrm{E}^{\prime}$ values below and above the $T_{\mathrm{g}}$ are also marked in Figure 10a. Generally speaking, a good SMP should have a change of $E^{\prime}$ of more than two to three orders below and above the $T_{\mathrm{g}}$.

Figure 10a shows that the E' of all of the SM-HEP-AM decreased by almost three orders of magnitude. The glass/rubber modulus ratio is defined as the elastic ratio, and higher elastic ratios would be beneficial to the SM-HEP-AM shape retention. The SM-HEP-AM with a larger glass/rubber modulus ratio below and above $T_{\mathrm{g}}$ is in favour of improving the shape fixity ratio [30]. Figure 10a also revealed that the glass modulus increased with the decreased JH-230 content. The molecular weight of the JH-230 is large $(2500 \mathrm{~g} / \mathrm{mol})$, and there exist lots of $-\mathrm{C}-\mathrm{O}-$ single bonds. The molecular chain rotates about a single bond, and the chain is very flexible, which decreased the intermolecular force and increased the mobility of the chain segment, thus leading to the decrease in the glass modulus of the SM-HEP-AM. According to different standards, $T_{\mathrm{g}}$ can be determined in several ways. In this study, the peak of the loss modulus versus temperature curve was defined as $T_{\mathrm{g}}$. The $T_{\mathrm{g}}$ values obtained from the loss modulus versus temperature curve are shown in Figure 10b. According to this definition, dynamic mechanical analysis (DMA) $T_{\mathrm{g}}$ gradually increased with a decreased JH-230 content. For a clearer illustration, the $T_{\mathrm{g}}$ values obtained from DSC and DMA are summarized in Figure 11. 


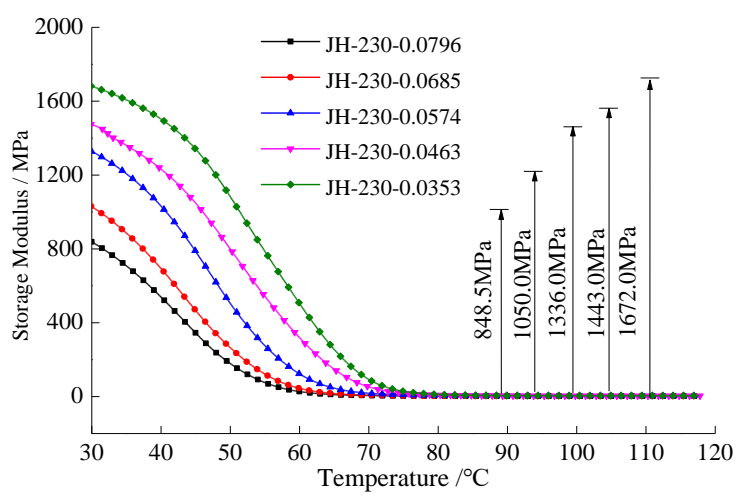

(a)

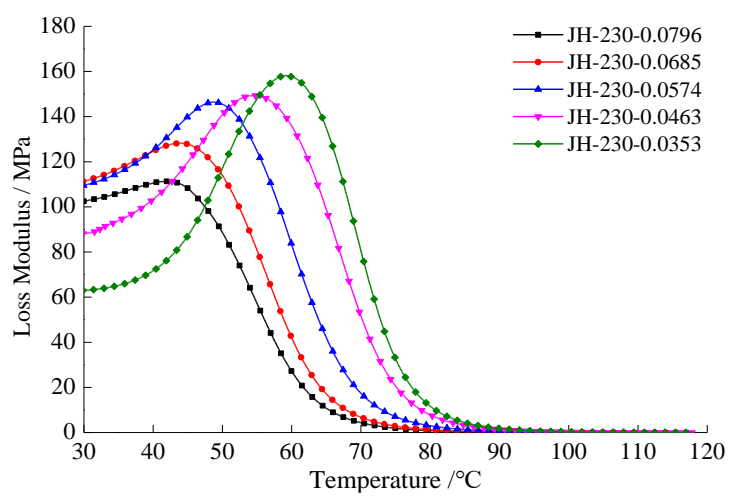

(b)

Figure 10. Dynamic mechanical analysis (DMA) curves of the SM-HEP-AM: (a) the storage modulus; and (b) the loss modulus.

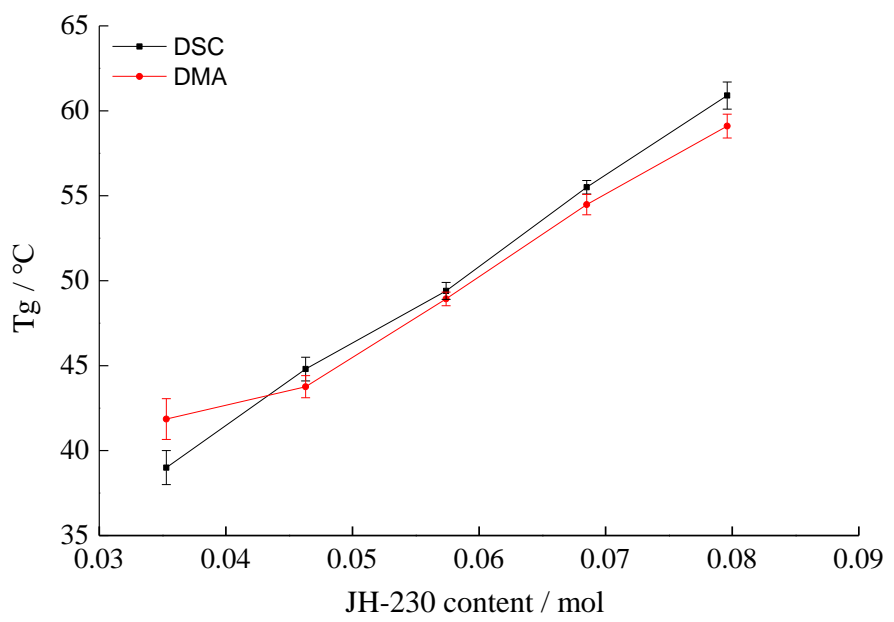

Figure 11. $T_{\mathrm{g}}$ values of the SM-HEP-AM.

The $T_{\mathrm{g}}$ values obtained from DSC were almost consistent with those obtained from DMA. This difference can be explained by the frequency effect in the DMA test. It can be concluded that the formulations of the SM-HEP-AM obtained by the preparation method are reasonable.

\subsection{The Shape-Memory Performance of the Shape Memory Hydrogenated Epoxy Resin Used for Asphalt Mixtures (SM-HEP-AM)}

To investigate the shape-memory performance of the SM-HEP-AM, the specimens were tested at $T_{\mathrm{g}}-10, T_{\mathrm{g}}, T_{\mathrm{g}}+10$, and $T_{\mathrm{g}}+20^{\circ} \mathrm{C}$ using the tensile-recovery shape memory test. The $T_{\mathrm{g}}$ values were obtained from DSC. According to the results, the shape fixity ratio of the SM-HEP-AM could reach $98.5 \%$. Full recovery could be observed after only several minutes at $T_{\mathrm{g}}+10$ and $T_{\mathrm{g}}+20^{\circ} \mathrm{C}$, and the shape recovery ratio of the SM-HEP-AM could reach $92 \%$. It revealed that the SM-HEP-AM displayed a good shape memory performance.

Figure 12 showed the relationship between the shape recovery ratio and recovery time of the JH-230-0.0796, JH-230-0.0685, JH-230-0.0574, JH-230-0.0463, and JH-230-0.0353 specimens at different temperatures. As can be seen in Figure 12, it required less time to complete the shape recovery process at higher temperatures for the same specimen. The free volume of the SM-HEP-AM increased with increased temperature, and thus the frozen segments and the frozen force were gradually released. Therefore, the shape recovery time decreased as the temperature increased. According to the results, it has a relatively low recovery rate at the start and at the terminal stage. At the start stage, the molecular chain segments of the specimens were still frozen. It slowly moved under the excitation temperature. 
The release of the internal stress was followed by a relatively strong friction between the segments, thereby decreasing the recovery rate. As time went on, the molecular segments constantly adjusted, and friction between the segments decreased. Therefore, during the middle stage, the shape recovery rate was relatively high. At the terminal stage, the slope of the curve became flat. This can be explained by the possibility that the stored strain energy has been largely released at the middle stage, so the recovery rate became slow. The same trend in the shape-recovery rate has been noted for other shape memory epoxies and shape-memory composites [31,32].

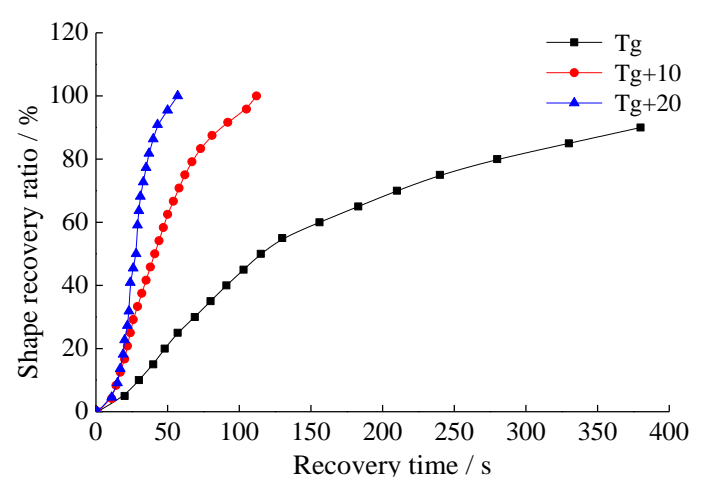

(a)

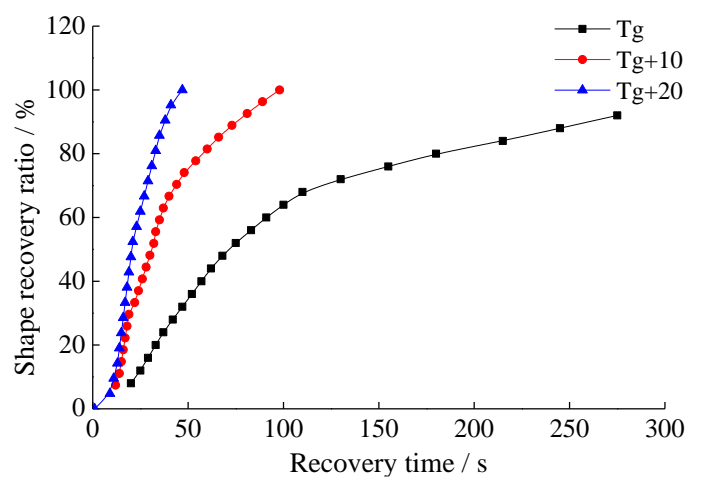

(c)

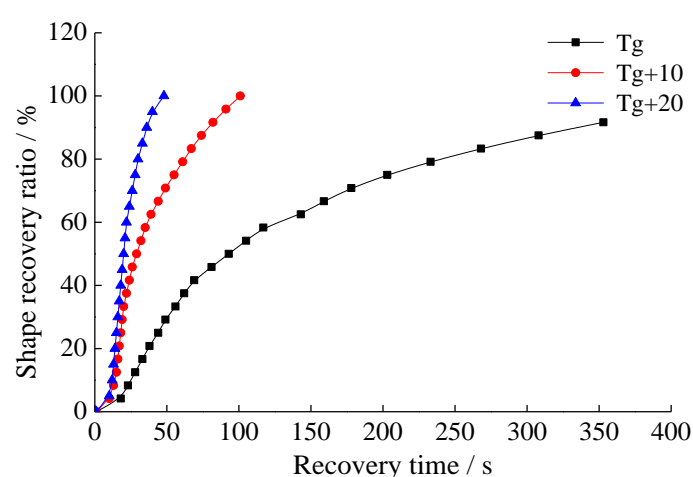

(b)

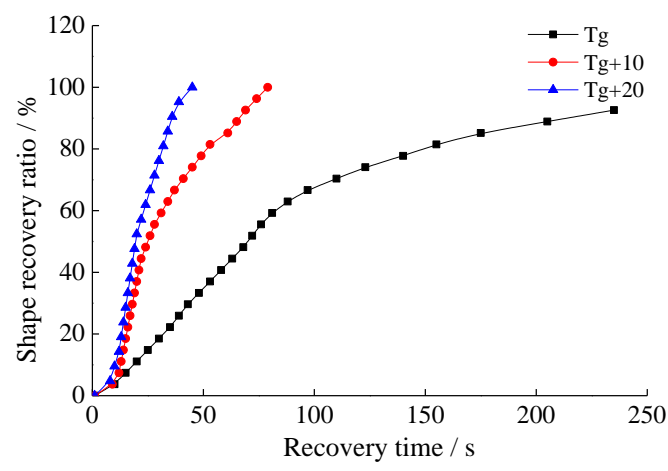

(d)

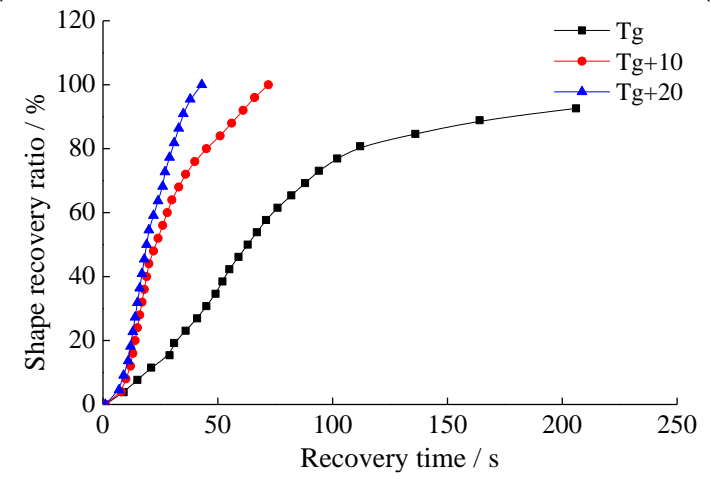

(e)

Figure 12. Relationship between shape recovery ratio and recovery time of the SM-HEP-AM: (a) JH-230-0.0796; (b) JH-230-0.0685; (c) JH-230-0.0574; (d) JH-230-0.0463; and (e) JH-230-0.0353.

The relationship of the shape recovery ratio and shape recovery time of the five specimens at $T_{\mathrm{g}}, T_{\mathrm{g}}+10$, and $T_{\mathrm{g}}+20^{\circ} \mathrm{C}$ are shown in Figure 13. When the temperature remained the same, the shape recovery time increased as the JH-230 content increased. Moreover, the trend between the shape recovery time and the $\mathrm{JH}-230$ content gradually decreased as the temperature increased. The crosslink density decreased with the increased JH-230 content. In the tensile-recovery shape memory test, strain energy was stored in the form of internal stress in a temporary shape. At a higher temperature, the 
SM-HEP-AM recovered its shape before deformation by using its energy in the form of a restoring force. From Figure 10a, the storage modulus decreased as the crosslink density decreased, which means that there was less strain energy stored as the crosslink density decreased, during which the specimen was deformed. The shape recovery time would increase as the crosslink density decreased. Thus, the recovery force decreased and the shape recovery time was extended.

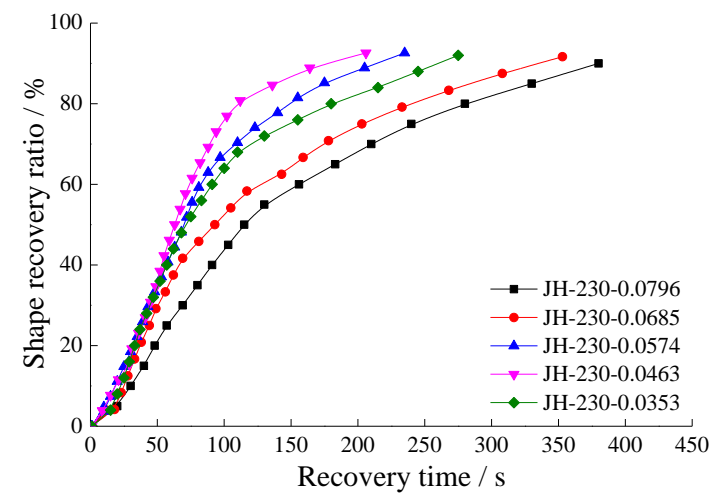

(a)

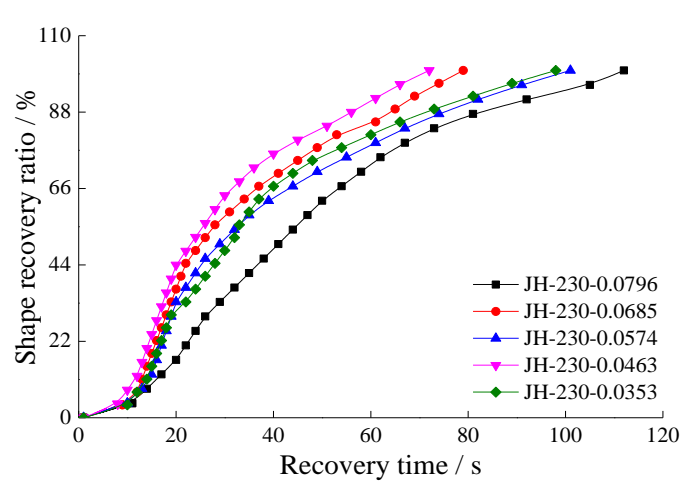

(b)

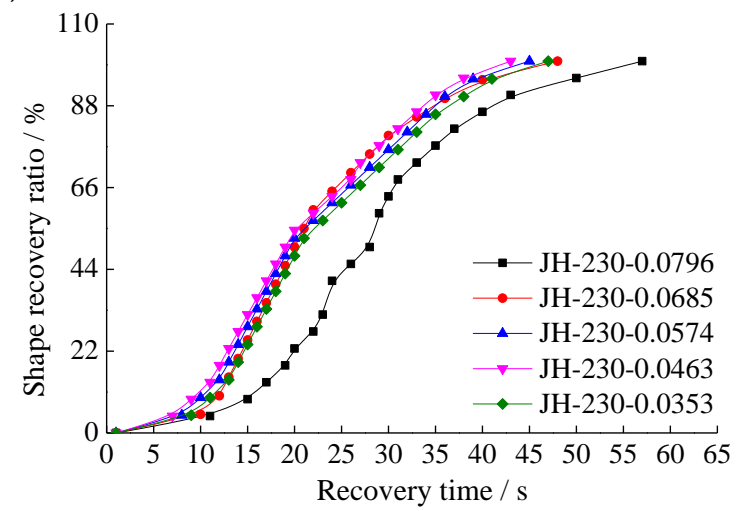

(c)

Figure 13. Relationship between the shape recovery ratio and recovery time of the SM-HEP-AM at the same temperature: (a) $\mathrm{T}_{\mathrm{g}}{ }^{\circ} \mathrm{C}$; (b) $\mathrm{T}_{\mathrm{g}}+10{ }^{\circ} \mathrm{C}$; and (c) $\mathrm{T}_{\mathrm{g}}+20^{\circ} \mathrm{C}$.

3.6. The Deformation Recovery Performance of the Asphalt Mixtures with and without the Shape Memory Hydrogenated Epoxy Resin Used for Asphalt Mixtures (SM-HEP-AM)

As can be seen from Figure 14, the deformation recovery ratio of the asphalt mixture mixed with the SM-HEP-AM has a higher deformation recovery ratio than that of the matrix asphalt mixture, and the deformation recovery ratio increased with the increase in the recovery time. The asphalt mixture is a typical viscoelastic-plastic material, and the obvious deformation occurred under a high temperature and continuous load. Asphalt mixture is one kind of self-healing material, so the deformation can partially recover. However, the self-healing process of the asphalt mixture is very slow. What's more, in practice, for asphalt mixture subjected to repeated loading, the asphalt mixture deformation is impossible to fully recover. In this paper, the SM-HEP-AM added to the asphalt is specimen JH-230 0.0796 , the corresponding $T_{\mathrm{g}}$ is $40^{\circ} \mathrm{C}$, and the recovery temperature is $60^{\circ} \mathrm{C}$. As the SM-HEP-AM is one kind of thermoset SMP, when the asphalt mixture mixed with the SM-HEP-AM was molded under a certain high temperature, the SM-HEP-AM was shaped and then retained the deformation under room temperature. It also caused partial deformation when the specimen was loaded. As the asphalt mixture mixed with the SM-HEP-AM was kept at $60^{\circ} \mathrm{C}$, the SM-HEP-AM was stimulated and produced a certain restoring force. The restoring force drove the surrounding materials, and finally improved the asphalt mixture deformation recovery performance. Therefore, the deformation recovery 
performance of the asphalt mixture mixed with the SM-HEP-AM increased. It can be concluded that applying the SM-HEP-AM to asphalt mixture at a temperature higher than the $T_{\mathrm{g}}$ of the used SM-HEP-AM may improve the deformation recovery performance of the asphalt mixture and slow down the accumulation of plastic deformation.

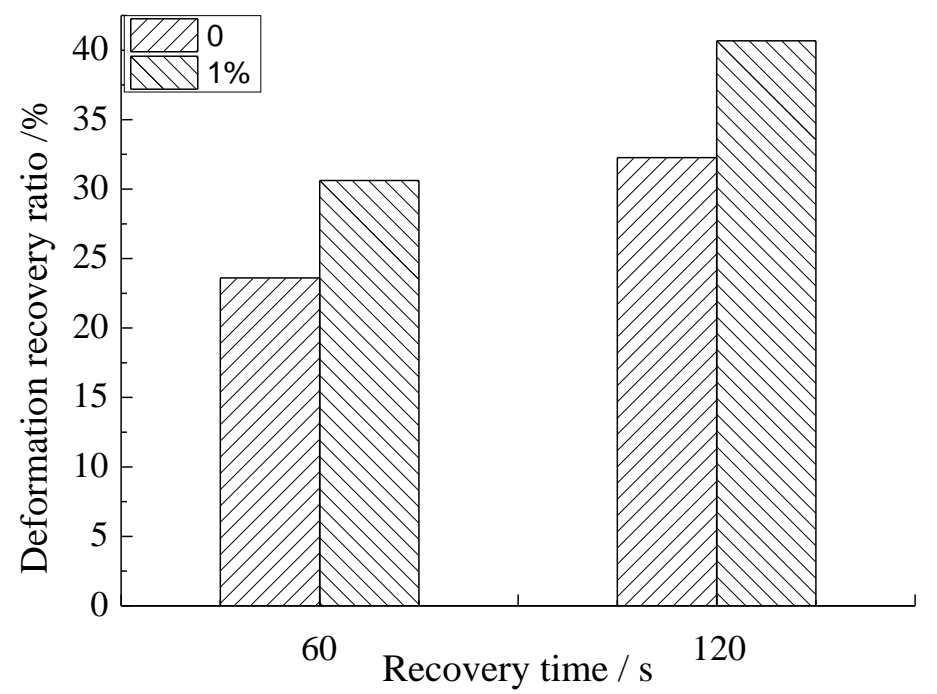

Figure 14. The deformation recovery ratio of the asphalt mixture and asphalt mixture mixed with the SM-HEP-AM.

\section{Conclusions}

In this paper, a new type of shape-memory hydrogenated epoxy resin (SM-HEP) was prepared from hydrogenated bisphenol A epoxy resin (AL-3040), polypropylene glycol diglycidyl ether (JH-230), and isophorone diamine (IPDA). The preparation of SM-HEP used for asphalt mixture (SM-HEP-AM) showed that the fitted glass-transition temperature $\left(T_{\mathrm{g}}\right)$ and measured $T_{\mathrm{g}}$ are almost the same. It was concluded that the needed $T_{\mathrm{g}}$ of the SM-HEP specimen can be accurately obtained by the preparation method. Furthermore, when IPDA has a fixed content of $0.5 \mathrm{~mol}$, we can predict the $T_{\mathrm{g}}$ when JH-230 has a content ranging from 0.0796 to 0.0353 , and the required $T_{\mathrm{g}}$ ranges from 40 to $60{ }^{\circ} \mathrm{C}$. The DSC results demonstrated that the SM-HEP-AM $T_{\mathrm{g}}$ decreased with the increased JH-230 content. This may be explained by the increase in the JH-230 content decreasing the cross-link density, thus resulting in an increased segment mobility. The storage modulus of the SM-HEP-AM changed almost three orders magnitude below and above the $T_{\mathrm{g}}$, which means that the SM-HEP-AM is a good kind of SMP. Meanwhile, when the chain segment mobility increased, the glass modulus increased as the $\mathrm{JH}-230$ content decreased. The changes in the relationship between the JH-230 content and $T_{\mathrm{g}}$ in the loss modulus versus temperature curve tested by DMA is consistent with the DSC results. As for the SM-HEP-AM with the same formulation, the $T_{\mathrm{g}}$ measured by DSC and that obtained by DMA were almost uniform. The SM-HEP-AM revealed a good shape-memory performance, and the full recovery can be observed after only several minutes at $T_{\mathrm{g}}+10$ and $T_{\mathrm{g}}+20^{\circ} \mathrm{C}$. The SM-HEP-AM specimens require less time to complete the shape recovery process at higher temperatures than at lower temperatures. On account of the influence of the crosslink density, the shape recovery time decreased with the decreased JH-230 content. The deformation recovery performance of the asphalt mixture mixed with the SM-HEP-AM was better than that of the matrix asphalt mixture. This may provide a method to slow down the accumulation of plastic deformation.

Acknowledgments: The writers wish to acknowledge the financial support of this research by the "Twelfth five-year" National Science and Technology Support Plan (No. 2014BAG05B04), the Construction Science and Technology Project of Ministry of Transport of China (No. 2013318490010), and the Central University program (No. 310821175012). 
Author Contributions: Biao Ma built the overall framework. Xueyan Zhou built the trial protocol, carried out the experiments, analyzed the experimental data, and studied the results. Kun Wei discussed the test results. Yanzhen Bo carried out the experiments. Zhanping You professionally revised the whole paper and the corresponding grammar, spelling mistakes, and vague descriptions. All authors discussed and contributed to the manuscript.

Conflicts of Interest: The authors declare no conflict of interest.

\section{References}

1. Si, W.; Zhou, X.; Ma, B.; Li, N. The mechanism of different thermoregulation types of composite shape-stabilized phase change materials used in asphalt pavement. Constr. Build. Mater. 2015, 98, 547-558. [CrossRef]

2. Moghaddam, T.; Soltani, M.; Karim, M. Experimental characterization of rutting performance of Polyethylene Terephthalate modified asphalt mixtures under static and dynamic loads. Constr. Build. Mater. 2014, 65, 487-494. [CrossRef]

3. Gu, X.; Yuan, Q.; Ni, F. Analysis of factors on asphalt pavement rut development based on measured load and temperature gradient. China J. Highw. Transp. 2012, 25, 30-37.

4. Ma, B.; Zhou, X.; Liu, J.; You, Z.; Wei, K; Huang, X. Determination of specific heat capacity on composite shape-stabilized phase change materials and asphalt mixtures by heat exchanges system. Materials 2016, 9, 389. [CrossRef]

5. Ma, B.; Adhikari, S.; Chang, Y.; Ren, J.; Liu, J.; You, Z. Preparation of composite shape-stabilized phase change materials for highway pavements. Constr. Build. Mater. 2013, 42, 114-121. [CrossRef]

6. Ma, B.; Si, W.; Ren, J.; Wang, H.; Liu, F.; Li, J. Exploration of road temperature-adjustment material in asphalt mixture. Road Mater. Pavement 2014, 15, 659-673. [CrossRef]

7. Ma, B.; Wang, S.; Li, J. Study on application of PCM in asphalt mixture. Adv. Mater. Res. 2011, 168-170, 2625-2630. [CrossRef]

8. Kumar, V.; Sireesh, S. Rutting behavior of geocell reinforced base layer overlying weak sand subgrades. Procedia Eng. 2016, 143, 1409-1416. [CrossRef]

9. Sun, J. Chapter 9-Predictions of rutting on asphalt pavements. Struct. Behav. Asph. Pavements 2016, 17, 601-648.

10. Shafabakhsh, G.; Ani, O.J. Experimental investigation of effect of $\mathrm{Nano} \mathrm{TiO}_{2} / \mathrm{SiO}_{2}$ modified bitumen on the rutting and fatigue performance of asphalt mixtures containing steel slag aggregates. Constr. Build. Mater. 2015, 98, 692-702. [CrossRef]

11. Ziari, H.; Behbahani, H.; Kamboozia, N.; Ameri, M. New achievements on positive effects of nanotechnology zyco-soil on rutting resistance and stiffness modulus of glasphalt mix. Constr. Build. Mater. 2015, 101, 752-760. [CrossRef]

12. Christopher, M.; Nitin, S.Y.; Ken, G.; Roxanne, L.; Zach, J. Shape-memory polymer networks with $\mathrm{Fe}_{3} \mathrm{O}_{4}$ nanoparticles for remote activation. J. Appl. Polym. Sci. 2009, 112, 3166-3176.

13. Wang, C.; Huang, W.; Ding, Z.; Zhao, Y.; Purnawali, H. Cooling-/water-responsive shape memory hybrids. Compos. Sci Technol. 2012, 72, 1178-1182. [CrossRef]

14. Florence, P.; Antoniya, T.; Philippe, D.; Raquez, J. Shape-memory polymers for multiple applications in the materials world. Eur. Polym. J. 2016, 80, 268-294.

15. Metcalfe, A.; Desfaits, A.; Salazkin, I.; Yahia, L.; Sokolowski, W.; Raymond, J. Cold hibernated elastic memory foams for endovascular interventions. Biomaterials 2003, 24, 491-497. [CrossRef]

16. Gall, K.; Dunn, M.; Liu, Y.; Finch, D.; Lake, M.; Munshi, N. Shape memory polymer nanocomposites. Acta Mater. 2002, 50, 5115-5126. [CrossRef]

17. Pretsch, T.; Ecker, M.; Schildhauer, M.; Maskos, M. Switchable information carriers based on shape memory polymer. J. Mater. Chem. 2012, 22, 7757-7766. [CrossRef]

18. Ecker, M.; Pretsch, T. Multifunctional poly(ester urethane) laminates with encoded information. RSC Adv. 2014, 4, 286-292. [CrossRef]

19. Strandman, S.; Zhu, X. Biodegradable shape-memory polymers for biomedical applications. In Shape Memory Polymers for Biomedical Applications; Elsevier: Amsterdam, The Netherlands, 2015; pp. 219-245.

20. Karger, J.; Kéki, S. Recent advances in shape memory epoxy resins and composites. In Multifunctionality of Polymer Composites; Elsevier: Amsterdam, The Netherlands, 2015; pp. 822-841. 
21. Fritzsche, N.; Pretsch, T. Programming of Temperature-Memory Onsets in a Semicrystalline Polyurethane Elastomer. Macromolecules 2014, 47, 5952-5959. [CrossRef]

22. Bothe, M.; Pretsch, T. Bidirectional actuation of a thermoplastic polyurethane elastomer. J. Mater. Chem. A 2013, 1, 14491-14497. [CrossRef]

23. Amber, J.; Gyaneshwar, P.; Baur, J.W. Strain rate-and temperature-dependent tensile properties of an epoxy-based, thermosetting, shape memory polymer (Veriflex-E). Mech. Time-Depend. Mat. 2012, 16, $205-221$.

24. Loredana, S. Shape memory epoxy foams: New materials for aerospace applications. Mater. Sci. Forum 2012, 706, 165-172.

25. Kuo, P.; Sain, M.; Yan, N. Synthesis and characterization of an extractive-based bio-epoxy resin from beetle infested pinus contorta bark. Green Chem. 2014, 16, 3483-3493. [CrossRef]

26. Xie, T.; Xiao, X.; Cheng, Y. Revealing triple-shape memory effect by polymer bilayers. Macromol. Rapid Commun. 2009, 30, 1823-1827. [CrossRef] [PubMed]

27. Highway Ministry of Transport. Standard Test Methods of Bitumen and Bituminous Mixtures for Highway Engineering; China Communication Press: Beijing, China, 2011.

28. Menozzi, A.; Garcia, A.; Partl, M.; Schuetz, P. Induction healing of fatigue damage in asphalt test samples. Constr Build. Mater. 2015, 74, 162-168. [CrossRef]

29. Xie, T.; Rousseau, I. Facile tailoring of thermal transition temperatures of epoxy shape memory polymers. Polymer 2009, 50, 1852-1856. [CrossRef]

30. Sokolowski, W.; Tan, S. Advanced self-deployable structures for space applications. J. Spacecr. Rockets 2007, 44, 750-754. [CrossRef]

31. Wei, K.; Zhu, G.; Tang, Y.; Liu, T.; Xie, J. The effects of crosslink density on thermo-mechanical properties of shape-memory hydro-epoxy resin. J. Mater. Res. 2013, 28, 2903-2910. [CrossRef]

32. Wei, K.; Zhu, G.; Tang, Y.; Tian, G.; Xie, J. Thermomechanical properties of shape-memory hydro-epoxy resin. Smart Mater. Struct. 2012, 21, 055022. [CrossRef]

(C) 2017 by the authors. Licensee MDPI, Basel, Switzerland. This article is an open access article distributed under the terms and conditions of the Creative Commons Attribution (CC BY) license (http:/ / creativecommons.org/licenses/by/4.0/). 